\title{
Adsorption of Pyrene from Aqueous Solution by Clay and Sandy Soil
}

\author{
Ebuwa I. Osagie, Chiedu Owabor \\ School of Energy, Environment and Agric-Food, Cranfield University, Bedfordshire, UK \\ Email: e.i.osagie@cranfield.ac.uk
}

Received 17 August 2015; accepted 8 October 2015; published 12 October 2015

Copyright (C) 2015 by authors and Scientific Research Publishing Inc.

This work is licensed under the Creative Commons Attribution International License (CC BY). http://creativecommons.org/licenses/by/4.0/

c) (i) Open Access

\begin{abstract}
The adsorption behaviour of pyrene using clay and sandy soil under ambient conditions is investigated in this study. Adsorption equilibrium isotherms and adsorption kinetics experiments were carried out in solutions of pyrene concentrations $(50-250 \mathrm{mg} / \mathrm{l})$ by using clay and sandy soil as adsorbents. Adsorption models were used to predict the mechanisms involved. The adsorption kinetics data best fitted the pseudo-second order kinetic model. The isotherm model which best represented the data obtained was the Langmuir model. The adsorption from the aqueous solution was observed to be time dependent and equilibrium time was found to be 34 and 28 hours for clay and sandy soil, respectively. The rate of adsorption using the pseudo-second order rate expression for pyrene was 0.00088 and $0.00085 \mathrm{~min}^{-1}$ for clay and sandy soil, respectively.
\end{abstract}

\section{Keywords}

Pyrene, Adsorption Isotherms, Adsorption Kinetics, Pseudo-Second Order

\section{Introduction}

Various toxic chemicals such as polycyclic aromatic hydrocarbons (PAHs), heavy metals and dyes are continuously discharged into the environment as industrial waste, causing water, air and soil pollutants. These chemicals are recalcitrant, persistent and have low solubility in water but are highly lipophilic. The presence of these compounds in the environment is of considerable public health and ecological concern due to their toxicity. Hence, they are considered by many countries as priority pollutants to deal with. They are environmental hormones and carcinogens [1]. Pyrene and other polycyclic aromatic hydrocarbons (PAHs) are released from incomplete combustion processes originating in industry, domestic sources including cigarette smoke and motor vehicle exhaust as well as natural events such as forest fires [2]. Therefore, immediate attention to the effective treatment of PAHs is needed. 
Pyrene, one of common mutagenic polycyclic aromatic hydrocarbons (PAHs) in polluted soil, is difficult to be decomposed in the environment and has been listed as one of sixteen kinds of PAHs priority by the United States EPA [3]. In addition, pyrene is a powerful hydrophobic substance. Faced with an increasing contamination of water resources, adsorption technology has become widely used in water treatment plants since it is a well-established and powerful technique due to its high depuration efficiency [4]. Powered and granular activated carbon has been proven an effective adsorbent in adsorption process [5]. However, recently there have been attempts to exploit low cost material sources to remove trace organic and inorganic contaminants from wastewaters due to the relatively high cost of activated carbons. The aim of this study is to investigate the effectiveness of clay and sandy soil in adsorbing pyrene from an aqueous solution. The adsorption of pyrene is further evaluated by the common isotherms (e.g. Langmuir, Freundlich and Tempkin isotherms) and kinetic models (e.g. pseudo-first order and pseudo-second order models). Pyrene was used in this study to determine its sorption and desorption on clay and sandy soils. Its wide prevalence in soils gives it a higher advantage over other aromatics. Also, its sorption properties enable a large extent of organic pollutants to be retained by the soil. Also in contact, the presence of cohesive forces differentiates clay and soils from other adsorbents [6]. The adsorption isotherm and kinetics are used in describing the sorption data.

\section{Materials and Methods}

The clay and sandy soil used in this study were obtained from Ikpoba River, Benin City, Edo State, Nigeria. These soils were collected at a depth of $0.5-2.0 \mathrm{~m}$. The pretreatment of the samples was done by removing stones and other heavy particles. A $220 \mu \mathrm{m}$ mesh was used to remove the large non-clay fractions from the clay and a $2.5 \mathrm{~mm}$ mesh was used to sieve the sandy soil. Then the samples were dried overnight at $383 \mathrm{~K}$ in a vacuum oven and then stored in an air-tight container covered with a black polythene bag prior to the adsorption experiments as shown in Table 1.

The adsorbate, pyrene $\left(\mathrm{C}_{16} \mathrm{H}_{10}\right)$ with a molecular weight of 202.25 gm was obtained from a chemical laboratory in Benin City and was used as the representative compound of PAHs in this study. The initial concentrations of pyrene for adsorption experiments were 50 to $250 \mathrm{mg} / \mathrm{l}$. The distilled water used for sample preparation, dilution and solution was obtained from the Department of Chemical Engineering, University of Benin, Benin City, Edo State, Nigeria.

\section{Desorption Studies}

The rates of adsorption by the adsorbents (clay and sandy soil) were determined from the uptake levels of pyrene from aqueous solution in batch experiments before and after contact until equilibrium was reached in the clay and sandy soil. $100 \mathrm{ml}$ of pyrene solutions with different initial concentrations (50 - $250 \mathrm{mg} / \mathrm{l}$ ) was placed in different tightly corked $1000 \mathrm{ml}$ flasks for clay and sandy soil, respectively. The slurry suspensions were sampled at intervals of 2 hours using UV spectrophotometer for sample analysis. To test the rate of the sorption process and investigate the potential rate controlling steps, a series of sample experiments at constant temperature was performed, the adsorption capacity $\left(q_{t}\right)$ was monitored and kinetic models were investigated. The sorption kinetics was tested by the pseudo-first order model [7] and the pseudo-second order model [8].

Table 1. Characterization of natural clay and sandy soil (Physico-chemical Analysis). The clay and sandy soil samples were analyzed for their physico-chemical properties as shown in the table below.

\begin{tabular}{ccc}
\hline & Clay soil & Sandy soil \\
\hline $\mathrm{pH}$ & 5.5 & 9.0 \\
Moisture content (\%) & 52 & 27 \\
Bulk density $\left(\mathrm{g} / \mathrm{cm}^{3}\right)$ & 1.624 & 3.192 \\
Surface area $(\mathrm{mg} / \mathrm{g})$ & 4.102 & 9 \\
Porosity $(\%)$ & 14 & 3.324 \\
\hline
\end{tabular}


The uptake of pyrene at equilibrium, $q_{e}(\mathrm{mg} / \mathrm{g})$ was calculated by the following expression:

$$
\begin{aligned}
& q_{e}=\frac{\left(C_{o}-C_{e}\right) V}{W} \\
& q_{t}=\frac{\left(C_{o}-C_{t}\right) V}{W}
\end{aligned}
$$

where $q_{e}$ and $q_{t}$ are the amount of naphthalene, benzene or pyrene absorbance per gram of adsorbent and at time $t$, respectively.

$C_{o}, C_{e}$ and $C_{t}(\mathrm{mg} / \mathrm{L})$ are the initial and equilibrium concentrations at time $t$, of naphthalene, benzene and pyrene solution, respectively,

$V(\mathrm{~L})$ is the volume of solution,

$W(\mathrm{~g})$ is the weight of clay and sand particles respectively.

Pseudo-first order and pseudo-second order model are used in describing the sorption data

The pseudo first-order equation is given as

$$
\mathrm{d} q_{t} / \mathrm{d} t=k_{1}\left(q_{e}-q_{t}\right)
$$

where $q_{e}$ and $q_{t}$ are the sorption capacities at equilibrium and at time $t$ respectively (mg.g ${ }^{-1}$ ) and $k_{1}$ is the rate constant $\left(\mathrm{L} \cdot \mathrm{min}^{-1}\right)$ of the pseudo first order equation.

After integration and applying boundary conditions $t=0$ to $t=t$ and $q_{t}=0$ to $q_{t}=q_{t}$, the integrated form of the Equation (1) becomes

$$
\log \left(q_{e}-q_{t}\right)=\log q_{e}-k_{1} t
$$

The pseudo-second order chemisorption kinetic equation is expressed as

$$
\mathrm{d} q_{t} / \mathrm{d} t=k_{2}\left(q_{e}-q_{t}\right)^{2}
$$

where $q_{e}$ and $q_{t}$ are the sorption capacity at equilibrium and at time $t,\left(\mathrm{mg} \cdot \mathrm{g}^{-1}\right)$ respectively and $k_{2}$ is the rate constant of the pseudo-second order sorption $\left(\mathrm{g} \cdot \mathrm{mg}^{-1} \cdot \mathrm{min}^{-1}\right)$.

For the boundary conditions $t=0$ to $t=t$ and $q_{t}=0$ to $q_{t}=q_{t}$, the integrated form of the Equation (3) becomes:

$$
1 / q_{e}-q_{t}=1 / q_{t}+k_{2} t
$$

This is the integrated rate law for a pseudo-second order reaction. The above Equation (5) can be rearranged to obtain:

This has a linear form

$$
q_{t}=1 / 1 / k_{2} q_{e}^{2}+t / q_{e}
$$

$$
t / q_{t}=1 / k_{2} q_{e}^{2}+t / q_{e}
$$

\section{Results and Discussion}

\subsection{Effect of Varying Concentration on the Adsorption of Pyrene}

The results of the experimentation and computation analysis of the kinetic modeling of the adsorption of pyrene contaminated clay and sandy soil are presented. The potential for the two samples to adsorb the solutes have been exploited. Adsorption isotherm is useful to describe how solutes interact with adsorbents and it is very important to evaluate the feasibility of the adsorbate-adsorbent systems. The isotherm data explained by theoretical or empirical equations provides preliminary modeling steps which are desired forpractical operation. Adsorption isotherms of pyrene onto clay and sandy soil are presented in Figures 1-6.

Figures 1-4 show that the equilibrium concentration and the amount of pyrene adsorbed increases as the initial effluent concentration increased. The Langmuir, Freundlich and Tempkin Isotherm constants were calculated from the slope and intercepts of the graphs. The Langmuir Isotherm in Figure 1 gave the best fit, with the highest correlation coefficient $\left(\mathrm{R}^{2}=0.8204\right)$ for pyrene sorption with sandy soil. This is followed by the Langmuir isotherm in Figure 2 with a correlation coefficient $\left(\mathrm{R}^{2}=0.8058\right)$ for pyrene sorption onto clay. The 


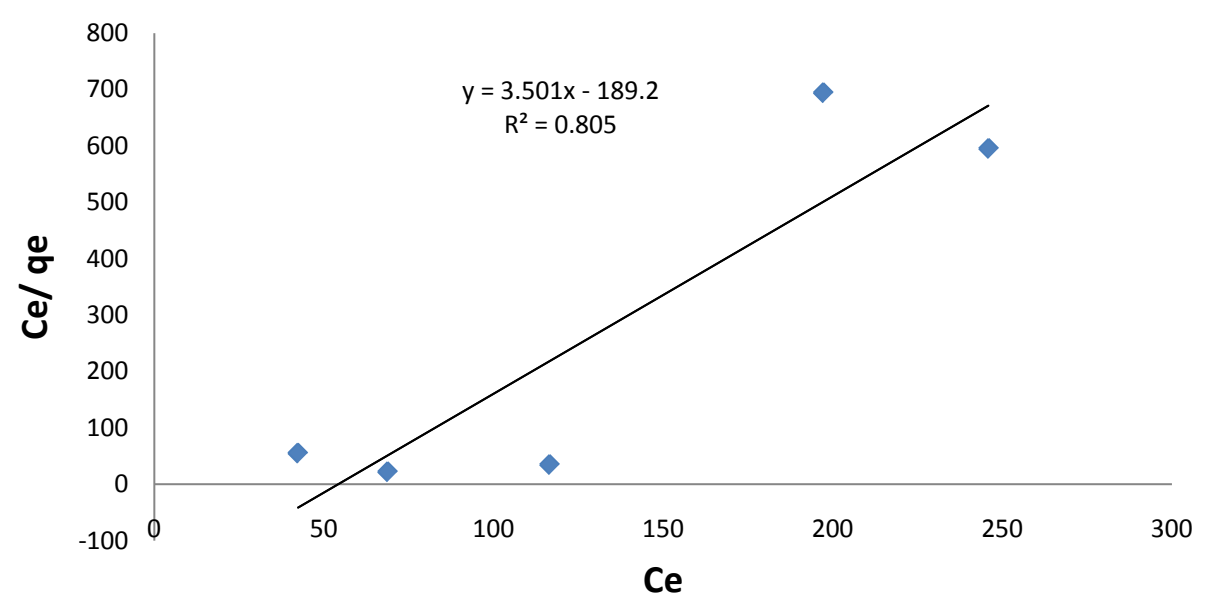

Figure 1. Langmuir plot of the variation of concentration of pyrene sorption with clay.

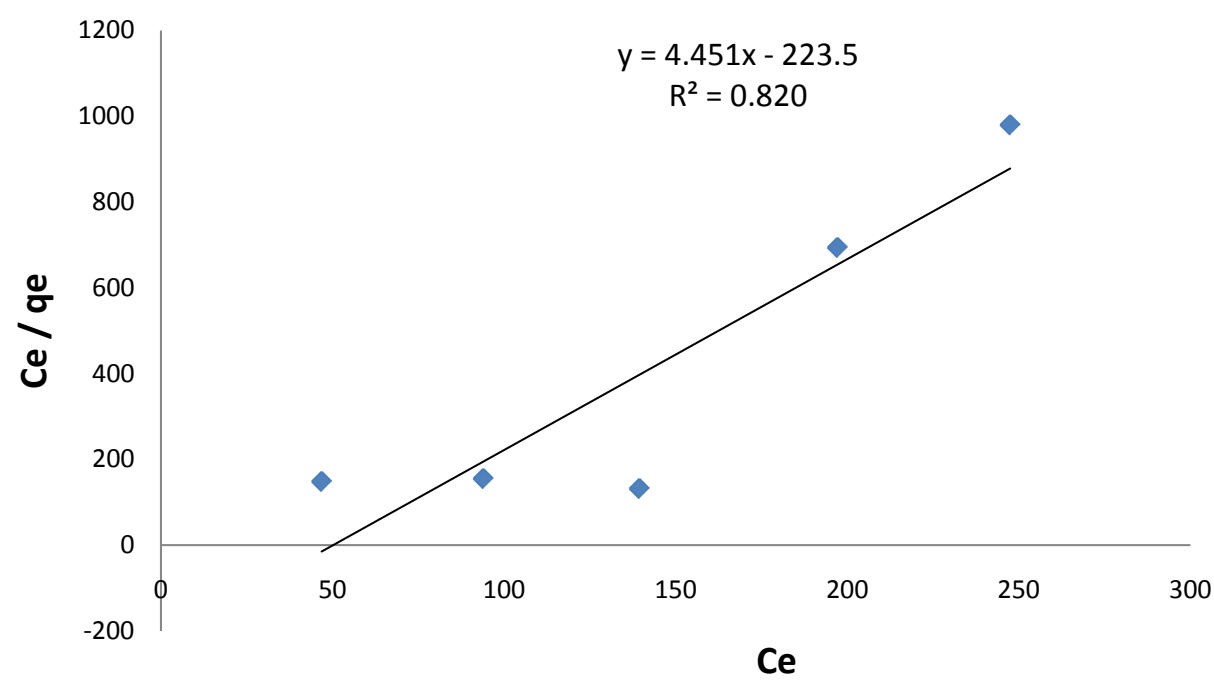

Figure 2. Langmuir plot for the variation of concentration of pyrene sorption with sandy soil.

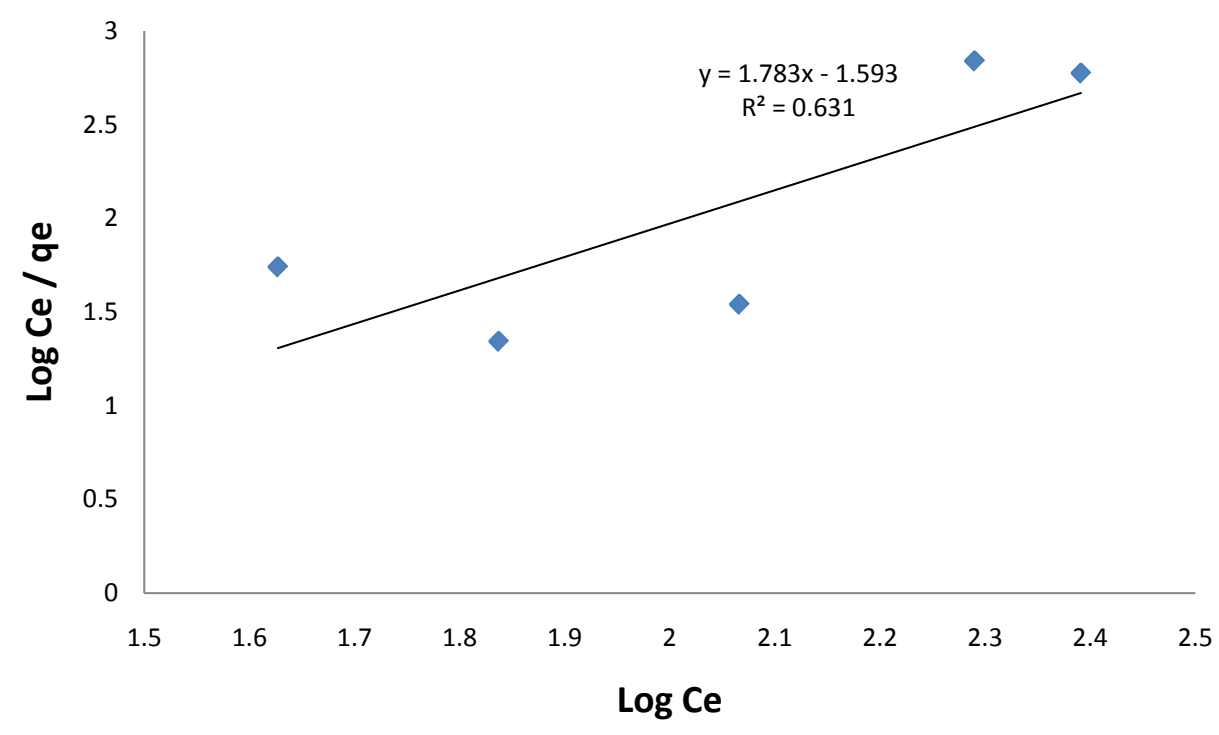

Figure 3. Freundlich plot for the variation of concentration of pyrene sorption with clay. 


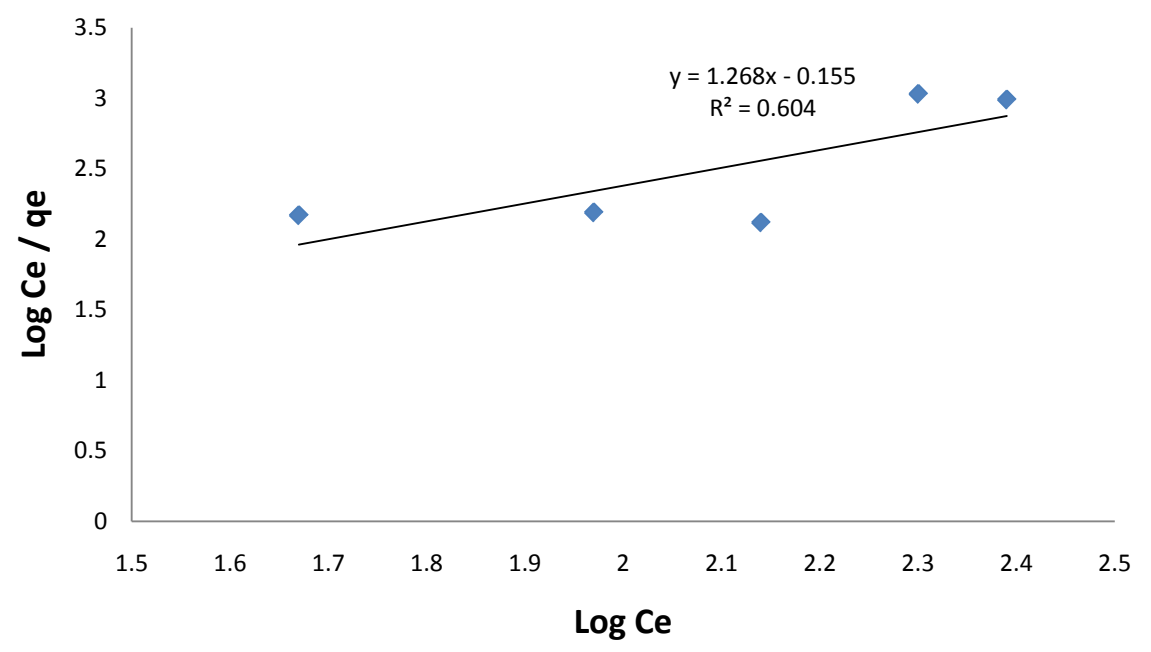

Figure 4. Freundlich plot for the variation of concentration of pyrene sorption with sandy soil.

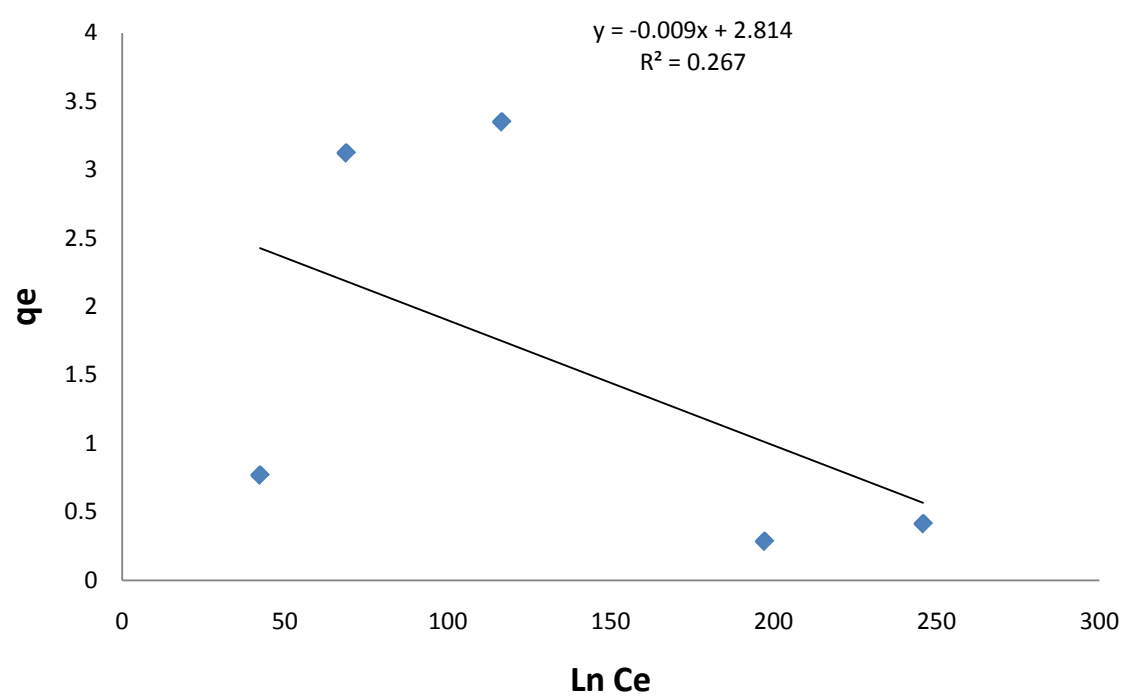

Figure 5. Tempkin plot for the variation of concentration of pyrene sorption with clay.

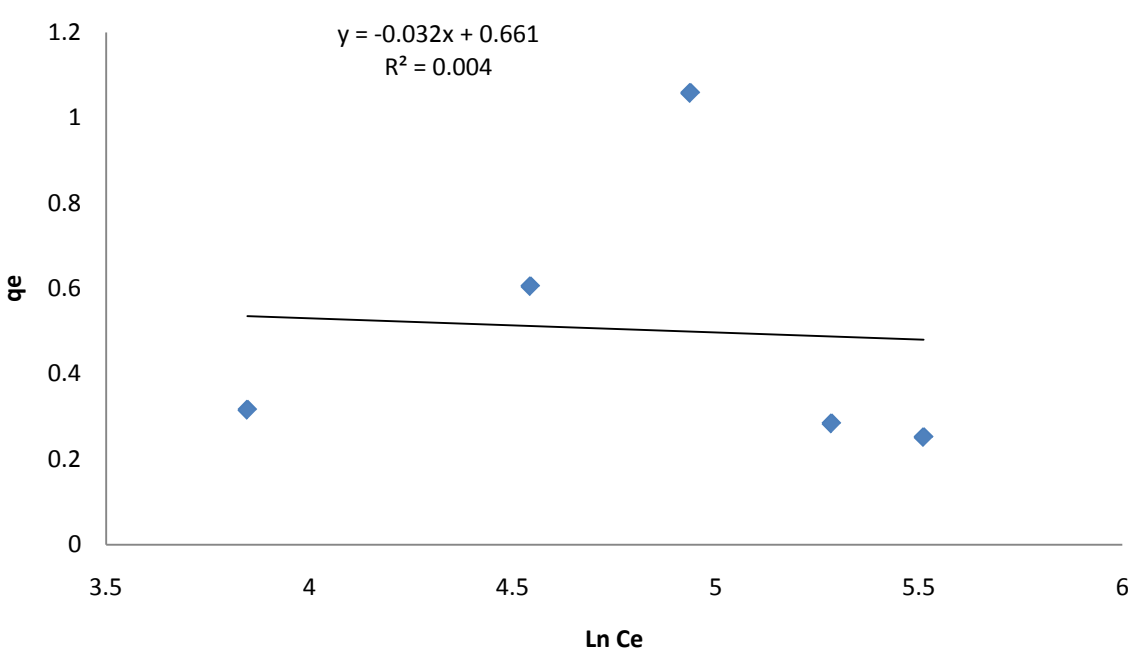

Figure 6. Tempkin plot for the variation of concentration of pyrene sorption with sandy soil. 
sorption process showed a good fit to the Langmuir isotherm which suggests a finite adsorption capacity and energetically equivalent sites [9]. The adsorption capacity Qo (mg/g) and adsorption intensity n for pyrene were 0.286, 0.561 and 0.225 and 0.789 for clay and sandy soil, respectively. Clay has a higher adsorption capacity than sandy soil. Therefore, clay will adsorb faster than sandy soil for pyrene.

The result indicated that for the Tempkin model, the data were not strongly correlated with the correlation coefficient $\mathrm{R}^{2}$ ranging from 0.004 to 0.2677 as shown in Figure 5 and Figure 6. Also the theoretical values obtained from the equation did not yield reasonable values. Thus, the rate of removal of pyrene from solution from the adsorbents; clay and sandy soil did not follow the Tempkin model in this study.

\subsection{Equilibrium Time and Agitation Time for Adsorption of Pyrene}

Figure 7 shows that equilibrium was achieved in 34 and 28 hours for pyrene in the clay and sandy soil, respecttively. There was a steady adsorption of pyrene by the two different adsorbents. Sandy soil was observed to reach equilibrium faster than clay for the contaminant solute, pyrene used in this study. This can be attributed to the large pore spaces, intra-porous nature of sandy soil (its pore spaces are connected to one another) and its high permeability [7].

Figure 8 shows that agitation time has an effect on the adsorption of pyrene from an aqueous solution. The amount of pyrene adsorbed increased as the agitation time increased until an equilibrium time was reached

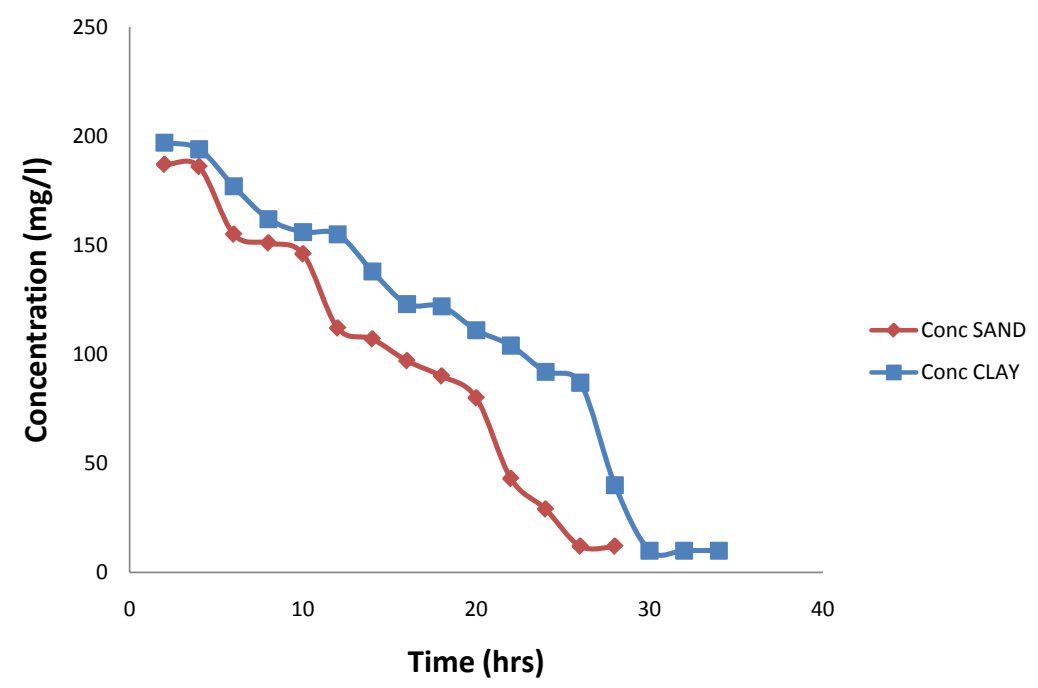

Figure 7. Variation of concentration with time for pyrene sorption in clay and sandy soil.

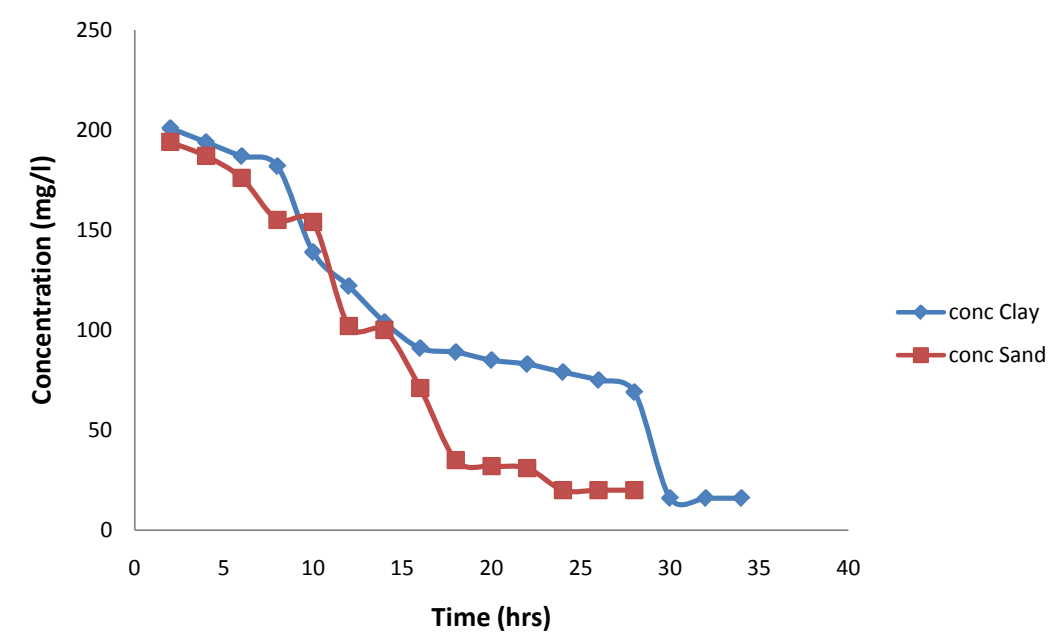

Figure 8 . The effect of agitation time on the adsorption of pyrene. 
beyond which the amount of removal becomes negligible and in the long run becomes constant. The sharp decrease in the curve for both clay and sandy soils indicates that significant adsorption is taking place at that particular time. The removal of pyrene is rapid in the initial stages of agitation time and gradually decreased with the lapse of time until saturation was attained. The removal curve is single, smooth and continuous indicating monolayer coverage of pyrene on the outer surface of the adsorbent [10]. The soils $\mathrm{pH}$ has a great impact on the adsorptive effects of the PAHs. As earlier published by Ebuwa et al. [11], benzene is seen to have very good adsorptive properties on the soils. However, pyrene has also shown similar characteristics, but pyrene is observed to take a longer time to adsorb sand and clay soils as when compared to benzene. The adsorptive effect of pyrene can be applied industrially in the separation of gas and liquid mixtures and this adsorptive separation can be accounted for in terms of kinetic mechanisms [12].

\section{Sorption Kinetics}

Table 2 shows the results of the kinetic modeling of the adsorption of pyrene onto clay and sandy soil used in this study. Comparing the values of the correlation coefficients $\mathrm{R}^{2}$ of pseudo-first order and pseudo-second order equations, the latter is better than the former and can be used to predict the adsorption kinetics of pyrene on clay and sandy soil. The value of the reaction rate constant $\mathrm{k}_{1}$ predicted for the adsorption kinetics by the pseudo-first order was found to be ambiguous. The value of the rate constant $K_{2}$ of pyrene adsorption in clay was 0.00088 $\mathrm{min}^{-1}$, while it is $0.00085 \mathrm{~min}^{-1}$ in sandy soil. The amount of pyrene adsorbed in the clay sample before equilibrium was $39.06 \mathrm{mg}$ while in the sandy soil, the amount was $34.05 \mathrm{mg}$. Based on the amount adsorbed, given equal times before equilibrium, clay could be described as a better adsorbing agent of pyrene than sandy soil. This property of clay over sandy soil can be attributed to its larger surface area and higher porosity than sandy soil [13]. Sandy soil has low porosity though not as many pore spaces because the grains are very large such that in a unit of sand, the fraction of soil volume that consists of holes is a lot less than for clay. Clay has many small pore spaces in which water containing the contaminant solutes remains clinging to the clay particle surfaces. Porosity is an important consideration when evaluating the potential volume of water or amount of hydrocarbons sediments may contain. Sediments with higher porosity typically have higher hydraulic conductivity, a property of sediments that describes the ease with which water can move through pore spaces [14].

\section{Conclusion}

The use of less expensive, single use sorbents to replace activated carbon is of significant interest. In this study, the ability of clay and sandy soil to bind pyrene, a member of the polycyclic aromatic hydrocarbons (PAHs), was investigated as a function of initial concentration. This study showed that adsorption of pyrene (PAHs) occurred in clay and sandy soil with clay adsorbing more of pyrene than sandy soil. The adsorptive property of clay over sandy soil was attributed to its large surface area, higher porosity and high hydraulic conductivity of the adsorbate. Adsorption increased as pyrene concentration increased. The results of the sorption experiments indicated that the kinetic model of pyrene sorption on clay and sandy soil followed the pseudo-second order model, whereas their isotherms were well described by the Langmuir model. The experimental results indicate that clay and sandy soil have considerable potential for the removal of the pollutant, pyrene.

Table 2. Kinetic parameters and correlation coefficient $\left(\mathrm{R}^{2}\right)$ for the adsorption of pyrene using clay and sandy soil.

\begin{tabular}{cccc}
\hline & Parameters & Clay & Sandy Soil \\
\hline Pseudo-first order & $\mathrm{K}_{1}$ & 1715 & 4507 \\
& $\mathrm{R}_{1}$ & -0.1192 & -0.2419 \\
& $q_{e}$ & 0.8620 & 0.8534 \\
Pseudo-second order & $\mathrm{K}_{2}$ & 0.00088 & 0.00085 \\
& $\mathrm{R}_{2}$ & 0.6058 & 0.7115 \\
\hline
\end{tabular}




\section{Acknowledgements}

The author is grateful for the financial support from the Vice-Chancellor, University of Benin, Benin City and the Federal Government Scholarship Board, Nigeria.

\section{References}

[1] Chang, C.-F., Chang, C.-Y., Chen, K.-H., Tsai, W.-T., Shie, J.-L. and Chen, Y.-H. (2004) Adsorption of Naphthalene on Zeolite from Aqueous Solution. Journal of Colloid and Interface Science, 277, 29-34. http://dx.doi.org/10.1016/j.jcis.2004.04.022

[2] Preuss, R., Angerer, J. and Drexler, H. (2003) Naphthalene-An Environmental and Occupational Toxicant. International Archives of Occupational and Environmental Health, 76, 556-576. http://dx.doi.org/10.1007/s00420-003-0458-1

[3] Tamamura, S., Sato, T., Ota, Y., Tang, N. and Hayakawa, K. (2006) Decomposition of Polycyclic Aromatic Hydrocarbon (PAHs) on Mineral Surface under Controlled Relative Humidity. Acta Geologica Sinica (English Edition), 80, 185-191. http://dx.doi.org/10.1111/j.1755-6724.2006.tb00229.x

[4] Bandosz, T.J. (2006) Activated Carbon Surfaces in Environmental Remediation. Academic Press, Waltham.

[5] Aksu, Z. and Yener, J. (2001) A Comparative Adsorption/Biosorption Study of Mono-Chlorinated Phenols onto Various Sorbents. Waste Management, 21, 695-702. http://dx.doi.org/10.1016/S0956-053X(01)00006-X

[6] Page, J. (1952) Role of Physical Properties of Clays in Soil Science. Clays and Clay Minerals, 1, 167-176. http://dx.doi.org/10.1346/CCMN.1952.0010119

[7] Yang, X.Y. and Al-Duri, B. (2005) Kinetic Modeling of Liquid-Phase Adsorption of Reactive Dyes on Activated Carbon. Journal of Colloid and Interface Science, 287, 25-34. http://dx.doi.org/10.1016/j.jcis.2005.01.093

[8] Wang, Y., Gao, B.-Y., Yue, W.-W. and Yue, Q.-Y. (2007) Adsorption Kinetics of Nitrate from Aqueous Solutions onto Modified Wheat Residue. Colloids and Surfaces A: Physicochemical and Engineering Aspects, 308, 1-5. http://dx.doi.org/10.1016/j.colsurfa.2007.05.014

[9] Hubbe, M.A., Rojas, O.J., Fingas, M. and Gupta, B.S. (2013) Cellulosic Substrates for Removal of Pollutants from Aqueous Systems: A Review. 3. Spilled Oil and Emulsified Organic Liquids. BioResources, 8, 3038-3097. http://dx.doi.org/10.15376/biores.8.2.3038-3097

[10] Sivraj, R., Namasivayam, C. and Kadirvelu, K. (2001) Orange Peel as an Adsorbent in the Removal of Acid Violet 17 (Acid Dye) from Aqueous Solution. Waste Manage, 21, 105-110. http://dx.doi.org/10.1016/S0956-053X(00)00076-3

[11] Osagie, E.I. and Owabor, C.N. (2015) Adsorption of Naphthalene on Clay and Sandy Soil from Aqueous Solution. Advances in Chemical Engineering and Science, 5, 345-361. http://dx.doi.org/10.4236/aces.2015.53036

[12] Yang, R.T. (2013) Gas Separation by Adsorption Processes. Butterworth-Heinemann, Oxford.

[13] Curry, C.W., Bennett, R.H., Hulbert, M.H., Curry, K.J. and Faas, R.W. (2004) Comparative Study of Sand Porosity and a Technique for Determining Porosity of Undisturbed Marine Sediment. Marine Georesources and Geotechnology, 22, 231-252. http://dx.doi.org/10.1080/10641190490900844

[14] Huang, W.L., Peng, P.A., Yu, Z.Q. and Fu, J.M. (2003) Effects of Organic Matter Heterogeneity on Sorption and Desorption of Organic Contaminants by Soils and Sediments. Applied Geochemistry, 18, 955-972. http://dx.doi.org/10.1016/S0883-2927(02)00205-6 